\title{
QUALIDADE DE VIDA NO TRABALHO: NA PERCEPÇÃO DOS PROFISSIONAIS DE SEGURANÇA PÚBLICA DA PREFEITURA MUNICIPAL DE MOSSORÓ/RN.
}

\author{
F. P. LIMA e S. M. ARAUJO \\ IFRN - Campus Ead \\ fpl-fabio@hotmail.com/sonia.araujo@ifrn.edu.br \\ Artigo submetido em 27/07/2018 e aceito em 01/08/2018 \\ DOI: 10.15628/empiricabr.2018.7556
}

\section{RESUMO}

A qualidade de vida no trabalho tem papel fundamental nas organizações. Neste sentido, esta pesquisa tem o objetivo de diagnosticar a qualidade de vida no trabalho sobre a percepção dos profissionais de segurança pública municipal de Mossoró/RN. Analisando sobre a qualidade de vida no trabalho dos guardas municipais, identificando dessa forma, os fatores que contribuem para qualidade de vida no trabalho, propondo alternativas de melhoria. A metodologia utilizada foi por meio de um questionário adaptado por Warken (2009) com questões numeradas de 1 á 6 de acordo com a escala Likert, sendo representada pelos fatores de discordância e concordância o qual foram aplicados 65 questionários obtendo uma amostragem no total de 30 respondentes no universo de 261 guardas municipais. A partir da análise dos resultados, observou-se que os guardas municipais em estudo estão insatisfeitos com seu ambiente de trabalho em alguns aspectos como remuneração, condições de segurança e saúde no trabalho, oportunidade e crescimento, condições de trabalho e manutenção da estrutura física e saúde no trabalho sendo possível identificar os fatores que interferem na qualidade de vida no trabalho (QVT) como aspectos físicos e psicológicos. Portanto, concluir-se que a pesquisa contribuiu para identificar os fatores que envolvem o ambiente de trabalho dos funcionários e influenciam na qualidade de vida no trabalho (QVT), dessa forma, após conhecer a percepção dos respondentes da pesquisa possibilita planejar ações e medidas que busquem propor um ambiente agradável e com mais qualidade para o servidor, que em consequência refletirá em melhores resultados para a organização.

PALAVRAS-CHAVE: Qualidade de vida no trabalho, Segurança Pública.

\section{ABSTRAT}

The quality of life at work has a fundamental role in organizations. In this sense, this research has the objective of diagnosing the quality of life in the work about the perception of professionals of municipal public safety of Mossoró / RN. Analyzing about the quality of life in the work of the municipal guards, thus identifying the factors that contribute to quality of life at work, proposing alternatives for improvement. The methodology used was a questionnaire adapted by Warken (2009) with questions numbered 1 to 6 according to the Likert scale, being represented by the factors of disagreement and agreement, which were applied 65 questionnaires obtaining a sample of a total of 30 respondents 


\section{ISSN - 2447-178X}

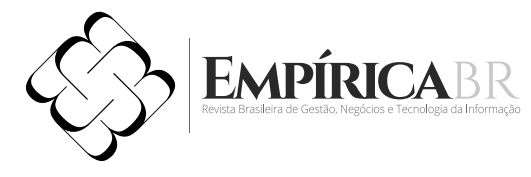

in the universe of 261 municipal guards. Based on the analysis of the results, it was observed that the municipal guards under study are dissatisfied with their work environment in some aspects such as compensation, safety and health conditions at work, opportunity and growth, working conditions and maintenance of physical structure and health at work and it is possible to identify the factors that interfere in quality of life at work (QWL) as physical and psychological aspects. Therefore, it was concluded that the research contributed to identify the factors that involve the work environment of the employees and influence the quality of life at work (QVT), in this way, after knowing the perception of the respondents of the research makes possible to plan actions and measures that seek to propose a pleasant and more quality environment for the server, which in consequence will reflect in better results for the organization.

KEYWORDS: Quality of life at work, Public Security.

\section{INTRODUÇÃO}

O atual cenário de insegurança e o crescente do índice da violência e criminalidade no país fazem com que aumente a preocupação com as questões relacionadas à segurança pública e ao combate ao crime, em que agentes da segurança pública enfrentam sérios problemas de infraestrutura para desenvolver seus trabalhos no dia a dia tendo impactos negativos dentro das organizações principalmente desse setor.

Diante desse cenário, surge á necessidade de conhecer sobre a gestão de pessoas aplicada aos profissionais de segurança pública para isso a problemática dessa pesquisa abordará a temática acerca da percepção que os servidores têm a respeito de qualidade de vida no trabalho. Um grande desafio da gestão de pessoas é fazer com que os colaboradores sintam-se bem com suas atividades de trabalhos e oferecer condições adequadas para que tenham melhor desempenho. (FERREIRA, 2012).

A pesquisa tem o objetivo geral diagnosticar a percepção dos profissionais da segurança pública referente às categorias de qualidade de vida no trabalho proposto pelo modelo de Walton(1973). Tendo como objetivos Específicos: Conhecer o perfil profissional da guarda municipal de Mossoró/ RN, identificar a percepção dos guardas municipais de Mossoró sobre a qualidade de vida no Trabalho, identificar os fatores que contribuem para qualidade de vida no trabalho, propor alternativas de melhoria da qualidade de vida dos guardas municipais.

0 trabalho apresenta como justificativa a necessidade de analisar a qualidade de vida no trabalho sobre a percepção dos profissionais da segurança pública da prefeitura de Mossoró-RN aplicando o modelo de Walton(1973), pois abrange uma análise que enfoca desde as necessidades básicas do ser humano até as condições da organização.

Portanto, o estudo caracterizará por uma pesquisa quantitativa empregando como delineamento o estudo de caso. A pesquisa foi realizada na área de segurança pública da prefeitura Municipal de Mossoró$\mathrm{RN}$, tendo como universo os guardas municipais compostos de um total de 261 guardas municipais ativos, o qual foi coletado os dados por meio de um questionário elaborado por Warken (2009) e adaptado de acordo com a escala likert numerada de 1 á 6 composta por indicadores sobre discordo ou concordo. 


\title{
2 REVISÃO BIBLIOGRÁFICA
}

\subsection{ADMINISTRAÇÃO PÚBLICA}

A administração é uma ferramenta indispensável para o bom gerenciamento de desempenho das organizacionais públicas, pois cabe à mesma pôr em ordem as riquezas existentes na organização, seja ela no âmbito operacional, gerencial ou estratégica. A administração é responsável pela tomada de decisão, definição das metas e objetivos, controle do desempenho e motivação dos funcionários.

Para Maximiano (2005, p. 06)

\begin{abstract}
Administração é o processo de tomar decisões sobre objetivos e utilização de recursos. 0 processo administrativo abrange cinco tipos principais de decisões, também chamadas processos ou funções: planejamento, organização, liderança, execução e controle.
\end{abstract}

A administração Pública, Segundo Granjeiro (2002, p. 23), "A administração Pública pode ser definida como o conjunto de órgãos e entidades destinados a satisfazer, de forma regular e contínua, as necessidades sociais nos termos da lei".

\subsection{GESTÃO DE PESSOAS}

Segundo Chiavenato (2010, p. 04), "o contexto de gestão de pessoas é formado por pessoas e organizações. As pessoas passam boa parte de suas vidas trabalhando dentro de organizações, e estas dependem daquelas para poderem funcionar e alcançar sucesso". Dessa forma, trabalhar em um ambiente agradável e saudável colabora com o bem- estar dos servidores.

De acordo com Gil (2007, p. 17), "gestão de pessoas é a função gerencial que visa à cooperação das pessoas que atuam nas organizações para o alcance dos objetivos tanto organizacionais quanto individuais". A gestão de pessoas é a área da administração que as organizações precisam analisar para identificar os fatores que estão contribuindo para a qualidade de vida dos colaboradores pois é por meio dela que se obtêm os resultados esperados.

Ainda segundo o autor Gil (2007, p. 60), "A gestão de pessoas passa a assumir um papel de liderança para alcançar a excelência organizacional necessária para enfrentar desafios competitivos, tais como a globalização, a utilização das novas tecnologias e a gestão do capital intelectual. ".

\subsection{QUALIDADE DE VIDA NO TRABALHO DOS SERVIDORES DE SEGURANÇA PÚBLICA}

A qualidade de vida no trabalho é um dos propósitos das organizações inseridas no atual cenário econômico onde a satisfação dos funcionários e o clima de trabalho contribui na obtenção dos resultados positivos na qualidade, na produtividade e no atendimento ao cliente, além de proporcionar um ambiente mais harmonioso e criativo sendo um diferencial competitivo para as empresas (Pontes, 2001). 


\section{ISSN - 2447-178X}

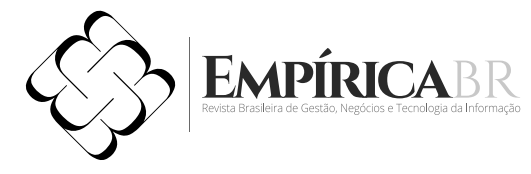

Segundo Bom Sucesso (1997, p. 29) a qualidade de vida trata da experiência emocional da pessoa com o seu trabalho, no momento em que tantas mudanças sociais e tecnológicas se instalam de forma intensa e acelerada. Abordando os efeitos desta realidade no bem-estar da pessoa do ponto de vista emocional, enfocando as consequências do trabalho sobre a pessoa e seus efeitos nos resultados da organização.

Dessa forma, Rodrigues (1998), afirma que a qualidade de vida no trabalho pode ser vista como "uma abordagem sócio-técnica em relação à organização do trabalho, tendo como base a satisfação do trabalhador no trabalho e em relação a ele".

Para Gil (2007), as organizações são desafiadas a fazer investimentos, tanto para induzir talentos quanto para melhorar o desempenho e a produtividade do trabalho, pois ao introduzir programas de qualidade de vida propicia aos empregados qualidade de vida com condições melhores atendendo suas necessidades. Uma vez que proporciona melhores resultados para as organizações, ou seja, colaboradores bem motivados serão mais produtivos.

O embasamento teórico de Walton (1973) segue uma categoria de conceitos que visam subsidiar e construir uma estrutura de análise sobre qualidade de vida no trabalho, diante disso, Fernandes (1996), define que a proposta metodológica baseia-se na perspectiva do termo "expressão do trabalhador", como sendo um elemento primordial para levantamento dos fatores ambientais; organizacionais; e comportamentais, sobre a percepção dos próprios integrantes da organização sendo satisfatórios ou não.

Segundo Chiavenato (2010, p. 490), os fatores de Walton que afetam a qualidade de vida no trabalho são:

1. Compensação justa e adequada: a justiça distributiva de compensação depende da adequação da remuneração ao trabalho que a pessoa realiza, da equidade interna (equilíbrio entre as remunerações dentro da organização) e da equidade externa (equilíbrio com as remunerações do mercado de trabalho).

2. Condições de segurança e saúde no trabalho: envolvendo as dimensões jornada de trabalho e ambiente físicos adequados à saúde e bem-estar da pessoa.

3. Utilização e desenvolvimento de capacidades: proporcionar oportunidades de satisfazer as necessidades de utilização de habilidades e conhecimentos do trabalhador, desenvolver sua autonomia, autocontrole e obter informações sobre o processo total do trabalho, bem como retro informação sobre o seu desempenho.

4. Oportunidades de crescimento contínuo e segurança: no sentido de proporcionar possibilidades de carreira na organização, crescimento e desenvolvimento pessoal e segurança no emprego de forma duradoura.

5. Integração social na organização: eliminação de barreiras hierárquicas marcantes, apoio mútuo, franqueza interpessoal e ausência de preconceito.

6. Constitucionalismo: refere-se ao estabelecimento de normas e regras da organização, direitos e deveres do trabalhador, recursos contra decisões arbitrárias e 


\section{ISSN - 2447-178X}

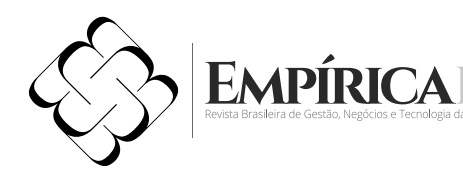

um clima democrático dentro da organização.

7. Trabalho e espaço total de vida: o trabalho não deve absorver todo o tempo e energia do trabalhador em detrimento de sua vida familiar e particular, de seu lazer e atividades comunitárias.

8. Relevância social da vida no trabalho: o trabalho deve ser uma atividade social que traga orgulho para a pessoa em participar de uma organização. A organização deve ter uma atuação e uma imagem perante a sociedade, responsabilidade social, responsabilidade pelos produtos e serviços oferecidos, práticas de emprego, regras bem definidas de funcionamento e de administração eficiente.

Portanto, Newstrom, (2001, pg.146), define que a "Qualidade de Vida no Trabalho (QVT) é dizer os pontos favoráveis e desfavoráveis de um ambiente de trabalho para as pessoas." Uma vez que desenvolver ambientes de trabalho que sejam tão bons para as pessoas proporcionando o bem -estar e desempenho dos colaboradores. Dessa forma, atendendo aos critérios de satisfação dos colaborados ao proporcionar qualidade de vida no trabalho.

\section{METODOLOGIA}

A pesquisa tem como base uma investigação empírica, por meio de métodos quantitativos, pois visa o levantamento de dados com o intuito de analisar o tema proposto, abordará um estudo de caso onde irá avaliar o objetivo do estudo por meio de um questionário elaborado por Warken (2009) e adaptado, segundo o modelo proposto por Walton(1973), uma vez que a analise aborda os fatores que afetam a qualidade de vida no trabalho desde as necessidades básicas do ser humano até as condições da organização.

Segundo Raupp e Beuren (2006), a pesquisa descritiva é um estudo intermediário entre a pesquisa exploratória e explicativa que, dentre outros aspectos, tem o significado de identificar, relatar e comparar aspectos ou comportamentos de determinada população, sem a interferência do pesquisador.

0 instrumento de pesquisa foi por meio de um questionário estruturado pela escala likert enumerado de 1 á 6 , sendo demonstrando pelos níveis de concordância e discordância para obtenção dos dados, onde os indicadores terá o objetivo de coletar dados sobre o desempenho e as competências dos profissionais de segurança pública em relação aos fatores que influenciam na qualidade de vida no trabalho. De acordo com Gil (2010) o estudo de caso é uma modalidade de pesquisa amplamente utilizada nas ciências biomédicas e sociais.

O universo é composto por um total de 261 guardas municipais efetivos da prefeitura de Mossoró sendo aplicados 65 questionários obtendo uma amostragem no total de 30 respondentes. Quanto à abordagem do tratamento e apresentação dos dados obtidos na pesquisa será por meio da elaboração de gráficos e tabelas dessa forma caracterizando como uma pesquisa quantitativa, pois visa apurar os dados de forma a compara com as variáveis que influenciam os fatores de qualidade de vida no trabalho. 


\section{ISSN - 2447-178X}

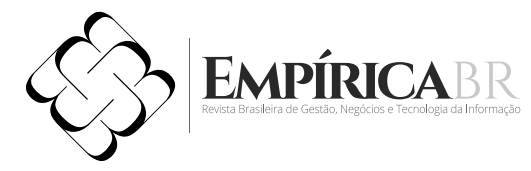

A instituição pesquisada caracteriza por ser uma um órgão público municipal, com objetivo de promover a segurança pública da cidade de Mossoró-RN. O período de coleta dos dados foram meses de setembro á outubro de 2017.

\section{ANÁLISE E DESCRIÇÃO DOS RESULTADOS}

Esta pesquisa caracteriza-se como um estudo de caso realizado na Guarda Municipal de Mossoró-RN constituído por um universo de 261 guardas municipais sendo aplicado um total de 65 questionários retornando 30 respondido. 0 questionário aplicado foi elaborado por Warken (2009) sendo adaptado para esta pesquisa.

Diante do exposto, foram analisados os resultados dos questionários aplicados que ficou dividido em dois momentos, o primeiro, na análise do perfil pessoal dos respondentes da instituição, e o segundo, momentos onde os guardas puderam avaliar questões referentes à qualidade de vida no trabalho de acordo com as oito fatores e critérios da qualidade propostas no modelo de QVT de Walton (1973), demostrados através de gráficos.

\subsection{Perfil dos respondentes:}

As características do perfil dos guardas municipais de Mossoró-RN sendo identificado pela primeira parte do questionário sendo composta por 4 perguntas estruturada, como gênero, idade, formação acadêmica e tempo de serviço na organização. 


\section{ISSN - 2447-178X}

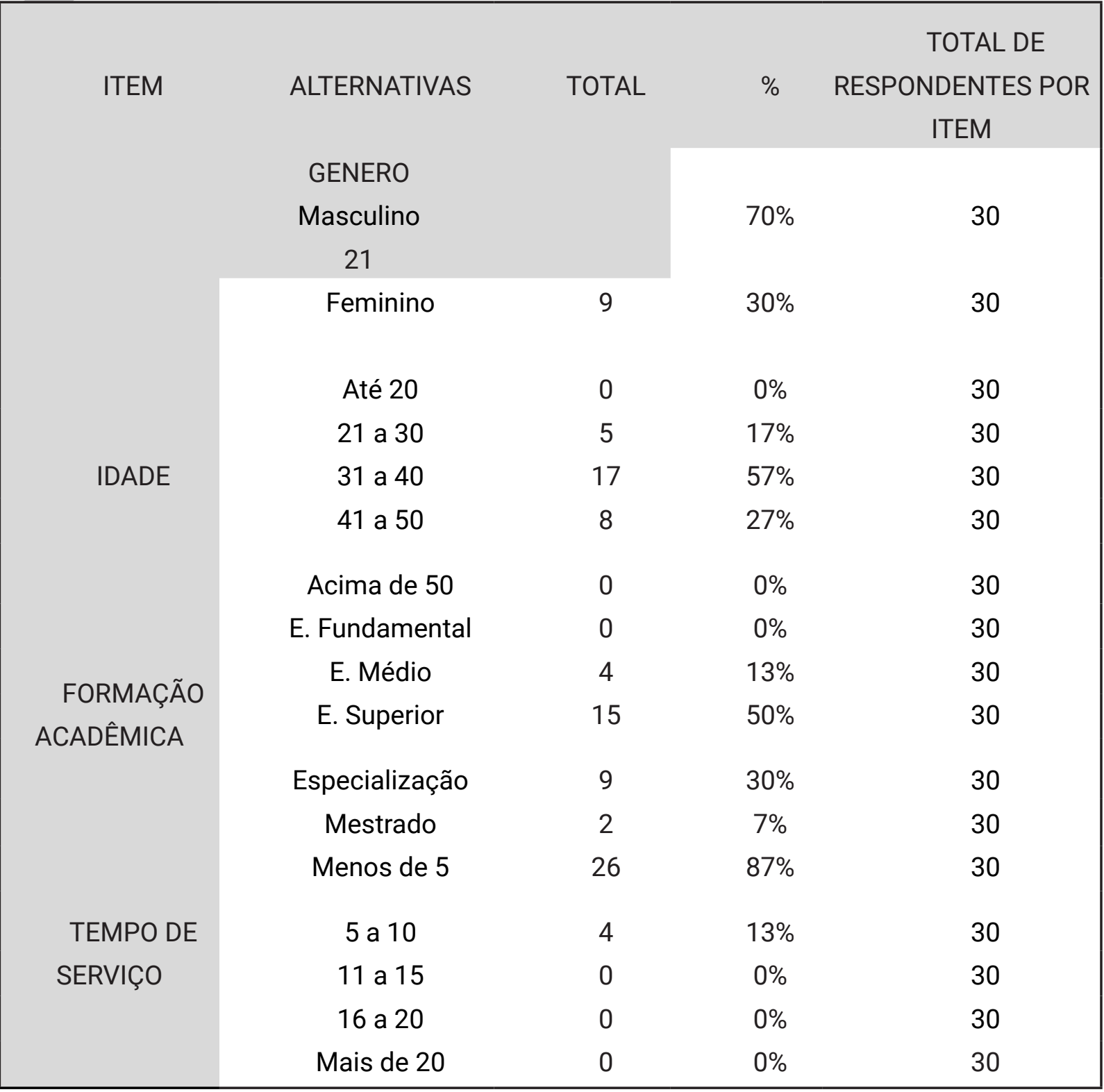

Tabela 01 - Perfil dos Guardas Municipais de Mossoró-RN

Fonte: Dados da pesquisa setembro/2017

A tabela 01 apresenta o gênero dos respondentes da pesquisa sendo que o gênero masculino representa a maior parte o sendo representado por $70 \%$ e $30 \%$ gênero feminino. Em relação à faixaetária de idade predominante dos respondentes da pesquisa foi de 31 a 40 anos com 57\% (cinquenta e sete) um percentual acentuado, dentro do quadro geral, no entanto, $8 \%$ estão entre 41 á 50 anos e $5 \%$ estão entre 21 á 30 anos já acima de 50 anos e ate 20 anos não tiveram respondentes.

Com relação à formação acadêmica, a tabela 01 mostra que 50\% (cinquenta) dos respondentes concluíram a graduação (ensino superior), 30\% (trinta) possuem especialização (pós- graduação), $13 \%$ possuem ensino médio e $7 \%$ possuem mestrado, já o ensino médio não ouve respondente. $E$ em relação ao tempo de serviço dos respondentes, $87 \%$ (oitenta e sete) dos guarda municipais tem menos de 5 anos na organização e 13\% (treze) entre 5 á 10 anos. 


\subsection{Indicadores de qualidade de vida no trabalho}

Nessa segunda parte são apresentadas as análises dos gráficos elaborados conforme estrutura do modelo de Walton (1973) sendo apresentados os oito fatores e critérios dos indicadores de qualidade de vida no trabalho.

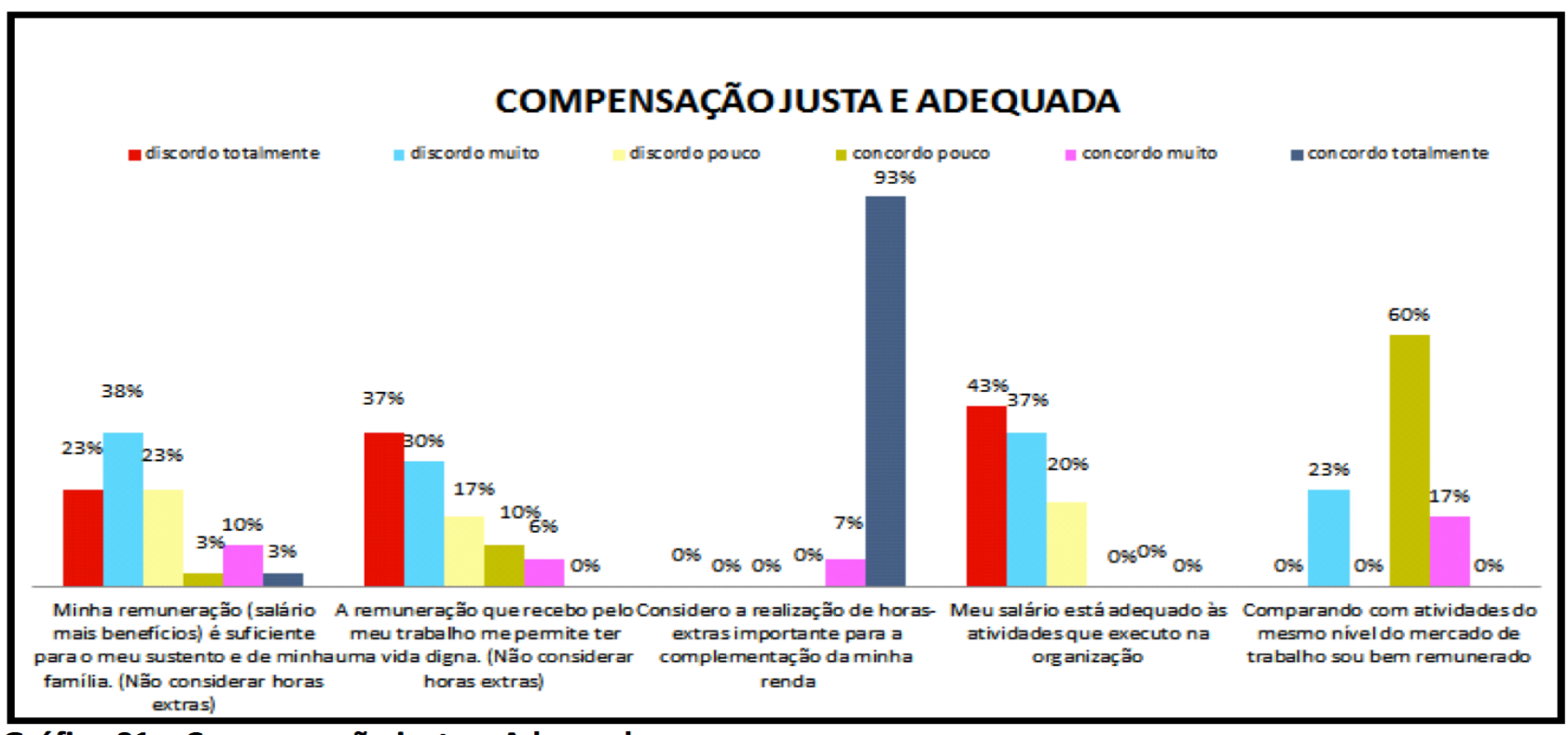

Figura 01 - Compensação justa e Adequada

Fonte: Dados da pesquisa setembro/2017

O gráfico 01 apresenta dados sobre os fatores de compensação justa e adequada na visão dos guardas municipais de Mossoró/RN, nesse critério, o modelo segundo Walton (1973) indica que sua análise é de suma importante para a organização. Dessa forma, os indicadores realizados foram sobre a remuneração (salário mais benefícios) é suficiente para o meu sustento e de minha família (não considerando horas extras) em relação a este indicador $84 \%$ responderam que discordaram totalmente, muito e pouco e apenas $16 \%$ concordaram totalmente, muito e pouco, ainda em relação ao indicador de remuneração, o valor recebido pelo trabalho permite ter uma vida digna. (Não considerando horas extras), sendo que $84 \%$ responderam que discordaram totalmente, muito e pouco e $16 \%$ concordaram totalmente, muito e pouco.

Os indicadores sobre a importância da realização de horas extra para a complementação da renda dos guardas municipais, os quais $100 \%$ dos respondentes concordaram totalmente e muito, e em relação ao salário ser adequado ás atividades que executam na organização 100\% dos respondentes discordaram totalmente, muito e pouco, entretanto, comparando as atividades do mesmo nível do mercado de trabalho em relação a ser bem remunerado, $77 \%$ dos respondentes concordaram muito e pouco e apenas $23 \%$ discordaram muito.

Para Walton (1973) a compensação justa e adequada refere-se à adequação da remuneração ao trabalho que a pessoa realiza, da equidade interna (equilíbrio entre as remunerações dentro da organização) e da equidade externa (equilíbrio com as remunerações do mercado de trabalho). 


\section{ISSN - 2447-178X}

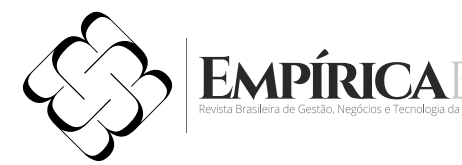

Dessa forma, constata-se que os fatores de compensação justa e adequada referente à qualidade de vida no trabalho sobre a percepção dos guardas municipais de Mossoró-RN, indicam que em relação à remuneração a mesma não está compatível com o trabalho desempenhado e que necessitam realizar horas extras para complementar a renda, sendo indispensável à realização da mesma. Mais comparando a remuneração em nível de mercado consideraram ser bem remunerado.

\subsubsection{Síntese de fator de compensação justa e adequada}

Tabela 02 - Compensação justa e Adequada

SINTESE DE FATOR DE COMPENSAÇÃO JUSTA E ADEQUADA

\begin{tabular}{|c|c|c|c|c|c|c|c|}
\hline & \multicolumn{3}{|c|}{ DISCORDO } & \multicolumn{3}{|c|}{ CONCORDO } & \multirow{2}{*}{$\begin{array}{c}\text { TOTAIS } \\
(\%)\end{array}$} \\
\hline & $\begin{array}{c}\text { Discordo } \\
\text { Totalmente } \\
(\%)\end{array}$ & $\begin{array}{l}\text { Discordo } \\
\text { muito } \\
(\%)\end{array}$ & $\begin{array}{c}\text { Discordo } \\
\text { pouco } \\
(\%)\end{array}$ & $\begin{array}{l}\text { Concordo } \\
\text { Totalmen } \\
\text { te }(\%) \\
\end{array}$ & $\begin{array}{l}\text { Concordo } \\
\text { muito } \\
(\%)\end{array}$ & $\begin{array}{l}\text { Concordo } \\
\text { pouco }(\%)\end{array}$ & \\
\hline $\begin{array}{l}\text { Minha remuneração } \\
\text { (salário mais } \\
\text { benefícios) é suficiente } \\
\text { para o meu sustento e } \\
\text { de minha família. } \\
\text { INão considerar horas } \\
\text { A remuneração que }\end{array}$ & 23 & 38 & 23 & 3 & 10 & 3 & 100 \\
\hline $\begin{array}{l}\text { recebo pelo meu } \\
\text { trabalho me permite } \\
\text { ter uma vida digna. } \\
\text { (Não considerar horas }\end{array}$ & 37 & 30 & 17 & 10 & 6 & 0 & 100 \\
\hline $\begin{array}{l}\text { Considero a realização } \\
\text { de horas-extras } \\
\text { importante para a } \\
\text { complementação da }\end{array}$ & 0 & 0 & 0 & 0 & 7 & 93 & 100 \\
\hline $\begin{array}{l}\text { Meu salário está } \\
\text { adequado às atividades } \\
\text { que executo na }\end{array}$ & 43 & 37 & 20 & 0 & 0 & 0 & 100 \\
\hline $\begin{array}{l}\text { atividades do mesmo } \\
\text { nível no mercado de } \\
\text { trabalho sou bem } \\
\text { remunerado }\end{array}$ & 0 & 23 & 0 & 60 & 17 & 0 & 100 \\
\hline Conjunto (\%) & 21 & 26 & 12 & 15 & 8 & 19 & 100 \\
\hline Totais agrupados (\%) & & 58 & & & 42 & & \\
\hline
\end{tabular}

O fator de compensação justa e adequada analisou-se a variável de acordo com os níveis de concordância e discordância demonstrando que um total de $58 \%$ dos guardas municipais "discordaram" e $42 \%$ "concordaram". Portanto, conclui-se que as variáveis representadas por remuneração e salário adequado apresentam como pontos que a organização pode realizar melhorias. 


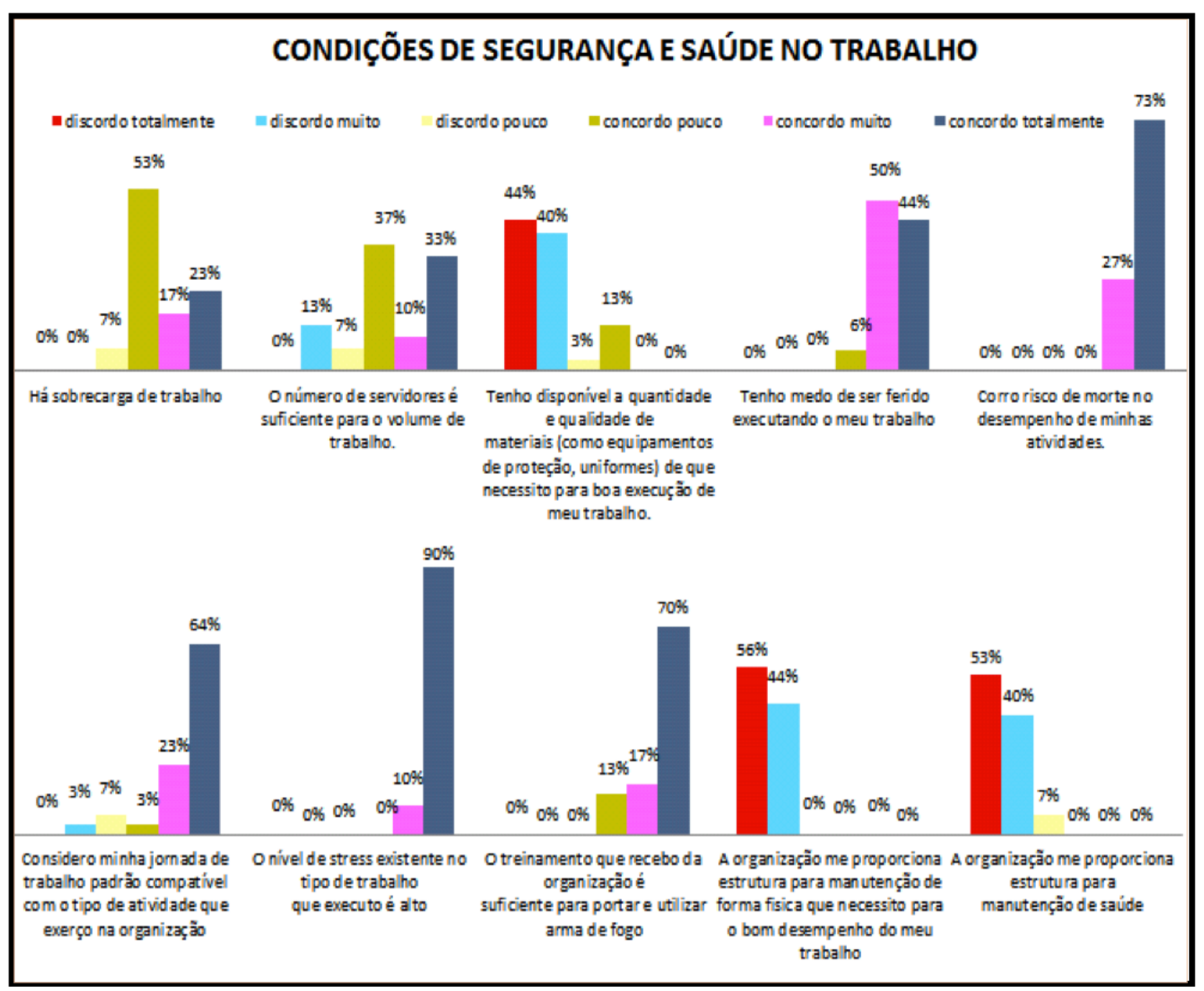

Figura 02 -Condição de saúde e segurança no trabalho

Fonte: Dados da pesquisa setembro/2017.

O gráfico 02 apresenta sobre os fatores de condições de segurança e saúde no trabalho na visão dos Guardas municipais de Mossoró/RN, nesse critério, o modelo proposto por Walton (1973), pois indica que sua análise é de suma importante para a organização. Os indicadores abordados foram sobre a existência de sobrecarga de trabalho, sendo que $93 \%$ dos servidores responderam que concordaram totalmente, muito e pouco e apenas $7 \%$ discordaram pouco. Outro indicador foi em relação ao número de servidores serem suficiente para o volume de trabalho, uma vez que, $80 \%$ responderam que concordaram totalmente, muito e pouco e apenas $20 \%$ discordaram muito e pouco.

0 terceiro indicador foi em relação à disponibilidade da quantidade e qualidade de materiais (como equipamento de proteção, uniformes) necessários para uma boa execução do trabalho diante disso, $87 \%$ responderam que discordaram totalmente, muito e pouco e apenas $13 \%$ concordaram pouco. Já o indicador sobre o medo de ser ferido executando o trabalho foi bastante relevante, uma vez que $100 \%$ responderam que concordaram totalmente, muito e pouco. Dessa forma o indicador sobre correr risco de morte no desempenho das atividades, também teve grande impacto, pois $100 \%$ responderam que concordaram totalmente e muito.

De acordo com os respondentes os indicadores de jornada de trabalho padrão ser compatível com o tipo de atividade que exercem na organização, sendo que $90 \%$ dos respondentes concordaram totalmente, muito e pouco e apenas $10 \%$ discordaram muito e pouco. Segundo os respondentes em relação ao nível de stress existente no tipo de trabalho executado ser alto, pois $100 \%$ concordaram 
totalmente e muito.

0 indicador sobre treinamento recebido pela organização ser suficiente para portar e utilizar arma de fogo, os quais $100 \%$ dos respondentes concordaram totalmente, muito e pouco. Em relação à organização proporcionar estrutura para manutenção de forma física que necessitam para o bom desempenho do trabalho, sendo que $100 \%$ dos responderam discordaram muito e totalmente. Outro indicador dessa variável foi em relação à organização proporcionar estrutura para manutenção da saúde dos respondentes sendo que $100 \%$ discordam totalmente, muito e pouco.

Para o autor Walton (1973) as condições de segurança e saúde no trabalho envolvem as dimensões de jornada de trabalho e ambiente físicos adequados à saúde e bem-estar da pessoa, diante disso aumenta a expectativa de vida, pois o maior tempo de vida trabalhando em atividades produtivas traz mais consciência do direito á saúde. (LIMONGI-FRANCA, 2009).

Portanto, diante dos indicadores apresentados percebe-se que o fator de condição de trabalho referente á saúde e segurança do servidor, demonstrando por meio dos dados que a organização não esta preocupada com a manutenção da estruturação física da organização e a manutenção da saúde do colaborador, pois na visão dos GCM estes são fatores relevantes para atentar aos critérios de qualidade de vida no trabalho, pois os índices de discordância apresentou a totalidade dos respondentes.

Outros indicadores que tiveram sua totalidade foi em relação á correr risco de morte no desempenho das atividades e o nível de stress existente no tipo de trabalho executado é alto, apresentando um grau de concordância em sua totalidade, pois apresenta um fator desfavorável tanto para o GCM como para a organização.

\subsubsection{Síntese de condições de segurança e saúde no trabalho}

O fator de condição de trabalho referente á saúde e segurança do trabalhador foram divididos em duas tabelas sendo que a primeira denominada de " $\mathrm{A}$ " refere-se á fatores existentes definidos pela organização e a segunda tabela denominada de "B" refere-se á fatores que demonstram como os guardas municipais se sentem em relação ao trabalho desempenhado.

Tabela 03 - Condição de Trabalho "A"

\begin{tabular}{|c|c|c|c|c|c|c|c|}
\hline & \multicolumn{3}{|c|}{ DISCORDO } & \multicolumn{3}{|c|}{ CONCORDO } & \multirow{2}{*}{$\begin{array}{r}\text { TOTAIS } \\
(\%)\end{array}$} \\
\hline & $\begin{array}{c}\text { Discordo } \\
\text { Totalmente } \\
(\%)\end{array}$ & $\begin{array}{c}\text { Discordo } \\
\text { muito } \\
(\%)\end{array}$ & $\begin{array}{c}\text { Discordo } \\
\text { pouco } \\
(\%)\end{array}$ & $\begin{array}{c}\text { Concordo } \\
\text { pouco } \\
(\%)\end{array}$ & $\begin{array}{l}\text { Concordo } \\
\text { muito } \\
(\%)\end{array}$ & $\begin{array}{c}\text { Concordo } \\
\text { Totalmente } \\
(\%)\end{array}$ & \\
\hline Jornada de trabalho & 0 & 3 & 7 & 3 & 23 & 64 & 100 \\
\hline $\begin{array}{l}\text { Número de servidores é } \\
\text { suficiente }\end{array}$ & 0 & 13 & 7 & 37 & 10 & 33 & 100 \\
\hline Material disponivel & 44 & 40 & 3 & 13 & 0 & 0 & 100 \\
\hline Treinamento suficiente & 0 & 0 & 0 & 13 & 17 & 70 & 100 \\
\hline Manutenção firma Fisica & 56 & 44 & 0 & 0 & 0 & 0 & 100 \\
\hline Manutenção Saude & 53 & 40 & 7 & 0 & 0 & 0 & 100 \\
\hline Conjunto (\%) & 26 & 23 & 4 & 11 & 8 & 28 & 100 \\
\hline Totais agrupados (\%) & & 53 & & & 47 & & \\
\hline
\end{tabular}

Fonte: Dados da pesquisa setembro/2017 


\section{ISSN - 2447-178X}

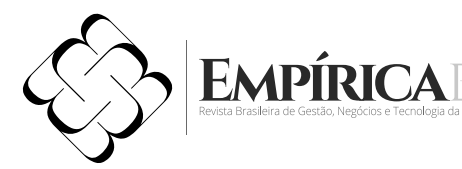

A tabela 03 representa que $53 \%$ dos respondentes discordaram e $47 \%$ concordaram. Pois a melhoria da saúde por meio de novas formas de organizar o trabalho é afetada por questões comportamentais que dizem respeito ás necessidades humanas e aos tipos de comportamentos individuais no ambiente de trabalho, de alta importância como variedade, identidade, tarefas e retro informações (LIMONGIFRANCA, 2009). Portanto, concluir-se que este fator está equilibrado diante a percepção dos GCM, cabendo poucas melhorias.

Tabela 04 - Condição de Trabalho "B"

\begin{tabular}{lcccccccc}
\hline \multicolumn{7}{c}{ SINTESE DE FATOR DE CONDIC ÃO DE TRABALHO "B" } \\
\hline & $\begin{array}{c}\text { Discordo } \\
\text { Totalmente }\end{array}$ & $\begin{array}{c}\text { Discordo Discordo } \\
\text { muito } \\
\text { pouco }\end{array}$ & $\begin{array}{c}\text { poncordo } \\
\text { pouco }\end{array}$ & $\begin{array}{c}\text { Concordo } \\
\text { muito }\end{array}$ & $\begin{array}{c}\text { Concordo } \\
\text { Totalmente }\end{array}$ & TOTAIS \\
\hline & $(\%)$ & $(\%)$ & $(\%)$ & $(\%)$ & $(\%)$ & $(\%)$ & \\
\hline Há sobrecarga de trabalho & 0 & 0 & 7 & 53 & 17 & 23 & 100 \\
Medo de ser ferido & 0 & 0 & 0 & 6 & 50 & 44 & 100 \\
Risco de morte & 0 & 0 & 0 & 0 & 27 & 73 & 100 \\
Stress & 0 & 0 & 0 & 0 & 10 & 90 & 100 \\
\hline Conjunto (\%) & 0 & 0 & 2 & 15 & 26 & 58 & 100 \\
\hline Totais agrupados (\%) & & 2 & & & 98 & &
\end{tabular}

Fonte: Dados da pesquisa setembro/2017

A tabela 04 retrata que o índice de insatisfação referente à qualidade de vida no trabalho é bastante grande sendo que $98 \%$ responderam que concordaram com essas variáveis e apenas $2 \%$ discordaram, ou seja, as relações de como os guardas se sentem perante á organização e ao trabalho refleti no desempenho das atividades como também na qualidade de vida. Para Bergamini (1998), explica que não basta oferecer os fatores higiênicos para motivar, quando atendidos, garantem apenas o bemestar físico dos profissionais, pois é um conjunto de fatores que contribui para a qualidade de vida no trabalho.

Portanto, ao analisar a motivação dos guardas municipais devem ser realizadas algumas considerações em relação ao indivíduo e o ambiente onde acontece. Pois o ambiente de trabalho pode ser um atenuante no nível de motivação e consequentemente na qualidade de vida no trabalho no que diz em relação às perspectivas dos indivíduos. (TADEUCCI ,2009) 


\section{USO E DESENVOLVIMENTO DAS CAPACIDADES}
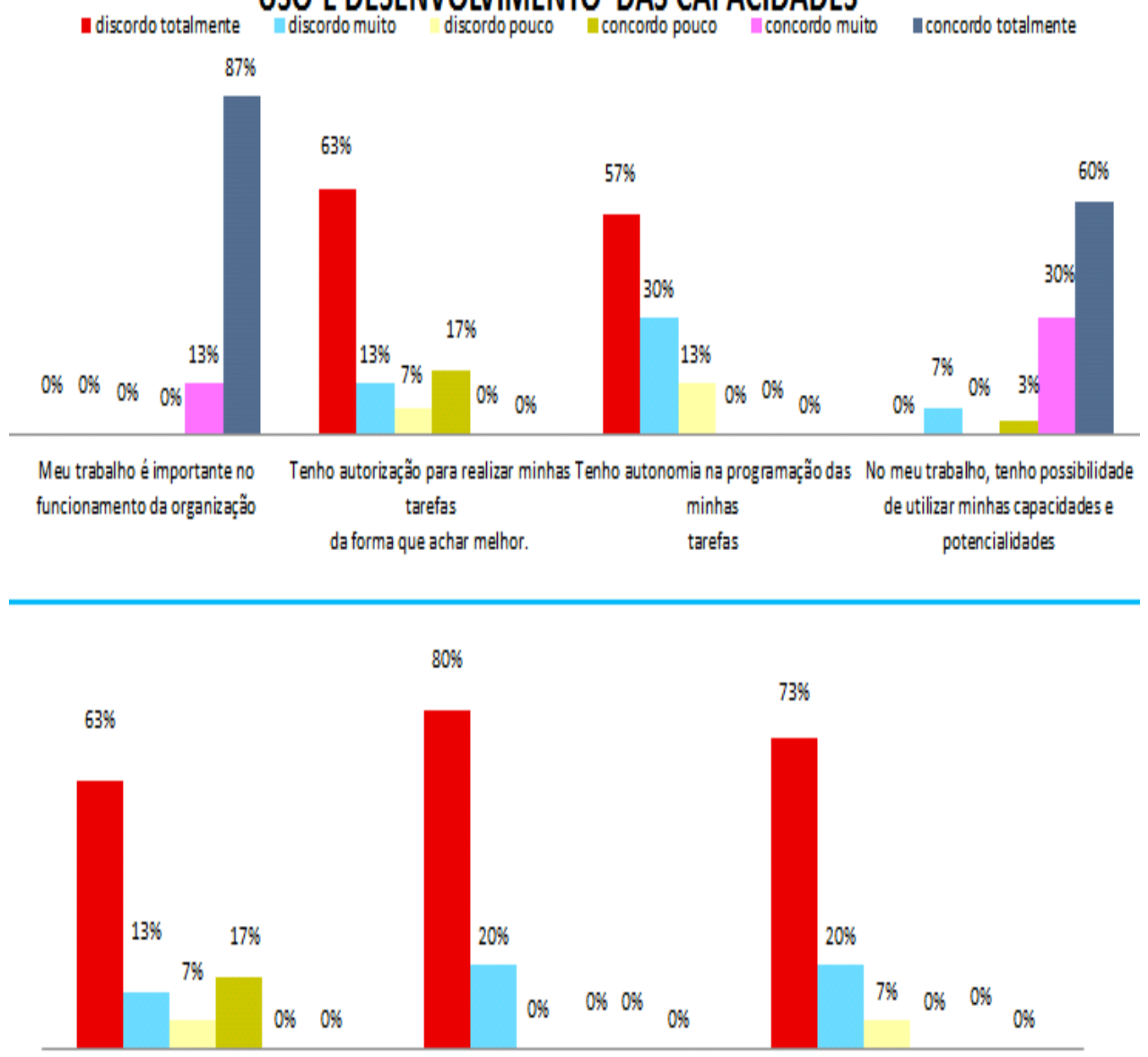

Recebo retorno de meus superiores quanto ao Recebo retorno de meus superiores quanto a0s A Guarda Municipal procura aproveitar talentos, desempenho positivo do meu trabalho pontos que devo melhorar em meu trabalho capacidades ou formação em cursos dos GM's na distribuição dos servidores em seu quadro

Figura 03 - Uso e desenvolvimento das Capacidades

Fonte: Dados da pesquisa setembro/2017

O gráfico 03 apresenta sobre os fatores de uso e desenvolvimento das capacidades no trabalho na visão dos Guardas municipais de Mossoró/RN, nesse critério, o modelo segundo Walton (1973) indica que sua análise mostra o desempenho da organização e o nível com que ela trata os respondentes. Dessa forma, os indicadores realizados foram sobre autorização para realizar as tarefas de forma que achar melhor, sendo que $83 \%$ discordaram totalmente, muito e pouco e apenas $17 \%$ concordaram pouco. Todos os respondentes reconhecem a importância do trabalho, uma vez que $100 \%$ concordaram totalmente e muito.

Em relação à autonomia na programação das tarefas $100 \%$ dos respondentes discordaram totalmente, muito e pouco. Outro indicador foi em relação à possibilidade de utilizar as capacidades e potencialidades no trabalho executado, pois $93 \%$ responderam que concordaram totalmente, muito e pouco e apenas $7 \%$ responderam que discordaram muito.

Dessa forma, os indicadores foram sobre o recebimento do retorno dos superiores quanto ao desempenho positivo do trabalho, ou seja, o feedback, pois nesse critério $83 \%$ discordaram totalmente, 
muito e pouco e apenas $17 \%$ concordaram pouco. Outro indicador também sobre o feedback dos superiores sobre os pontos que devem ser melhorado no trabalho, sendo que o total de $100 \%$ dos respondentes discordaram totalmente e muito. Entretanto, outro indicador apontado foi em relação da guarda municipal procurava aproveitar os talentos, capacidades ou formações em cursos dos GCM's na distribuição dos servidores em seu quadro mais o total dos $100 \%$ dos respondentes discordaram totalmente, muito e pouco.

\subsubsection{Síntese de fator de uso e desenvolvimento das capacidades}

Tabela 05 - Uso e desenvolvimento das Capacidades SINTESE DE FATOR DE USO E DESENVOLVIMENTO DAS CAPACIDADES

\begin{tabular}{|c|c|c|c|c|c|c|c|}
\hline & \multicolumn{3}{|c|}{ DISCORDO } & \multicolumn{3}{|c|}{ CONCORDO } & \multirow{2}{*}{$\begin{array}{c}\text { TOTAIS } \\
(\%)\end{array}$} \\
\hline & $\begin{array}{c}\text { Discordo } \\
\text { Totalmente } \\
(\%)\end{array}$ & $\begin{array}{c}\text { Discordo } \\
\text { muito } \\
(\%)\end{array}$ & $\begin{array}{c}\text { Discordo } \\
\text { pouco } \\
(\%)\end{array}$ & $\begin{array}{c}\text { Concordo } \\
\text { pouco } \\
(\%)\end{array}$ & $\begin{array}{c}\text { Concordo } \\
\text { muito } \\
(\%)\end{array}$ & $\begin{array}{l}\text { Concordo } \\
\text { Totalmente } \\
\text { (\%) }\end{array}$ & \\
\hline Importancia do trabalho & 0 & 0 & 0 & 0 & 13 & 87 & 100 \\
\hline Retorno desempenhado & 63 & 13 & 7 & 17 & 0 & 0 & 100 \\
\hline $\begin{array}{l}\text { Retorno pontos a } \\
\text { melhorar }\end{array}$ & 80 & 20 & 0 & 0 & 0 & 0 & 100 \\
\hline Autonomia programada & 57 & 30 & 13 & 0 & 0 & 0 & 100 \\
\hline Autonomia realizada & 63 & 13 & 7 & 17 & 0 & 0 & 100 \\
\hline Utiliza capacidades & 0 & 7 & 0 & 3 & 30 & 60 & 100 \\
\hline Aproveitamento & 73 & 20 & 7 & 0 & 0 & 0 & 100 \\
\hline Conjunto $(\%)$ & 48 & 15 & 5 & 5 & 6 & 21 & 100 \\
\hline Totais agrupados (\%) & & 68 & & & 32 & & \\
\hline
\end{tabular}

O fator de uso e desenvolvimento das capacidades mostra na percepção dos guardas municipais os critérios de como a organização administra á sua gestão. Pois de acordo, com a tabela 05 , um total de $68 \%$ dos respondentes discordaram e $32 \%$ concordaram, dessa forma, essas variáveis demonstram como os servidores se sentem em relação ao trabalho desempenhado, sendo fator relevantes os feedback da organização. Constata-se que a organização não procura aproveitar as capacidades dos GCM`s e também não dão autonomia em relação ao trabalho. Entretanto, esse fator prejudica a qualidade de vida no trabalho.

Para o autor Dolam (2006) a qualidade de vida no trabalho é um método pelo qual todos os membros do estabelecimento por meio dos canais de comunicação abertos e apropriados preparamse para tal fim, tem vozes nas decisões que afetam sua função, em especial, e ao ambiente de trabalho, em geral o que resulta em maior envolvimento e satisfação no trabalho e menos stress e exaustão.

Portanto, diante dos dados apresentados na tabela 05 , observa-se que a organização não dar o feedback das atividades desempenhas pelos guardas, como também não apresentam os pontos positivos e negativos, uma vez que esse fator é de suma importância na contribuição da melhoria continua dos colaboradores e em consequência no trabalho. 


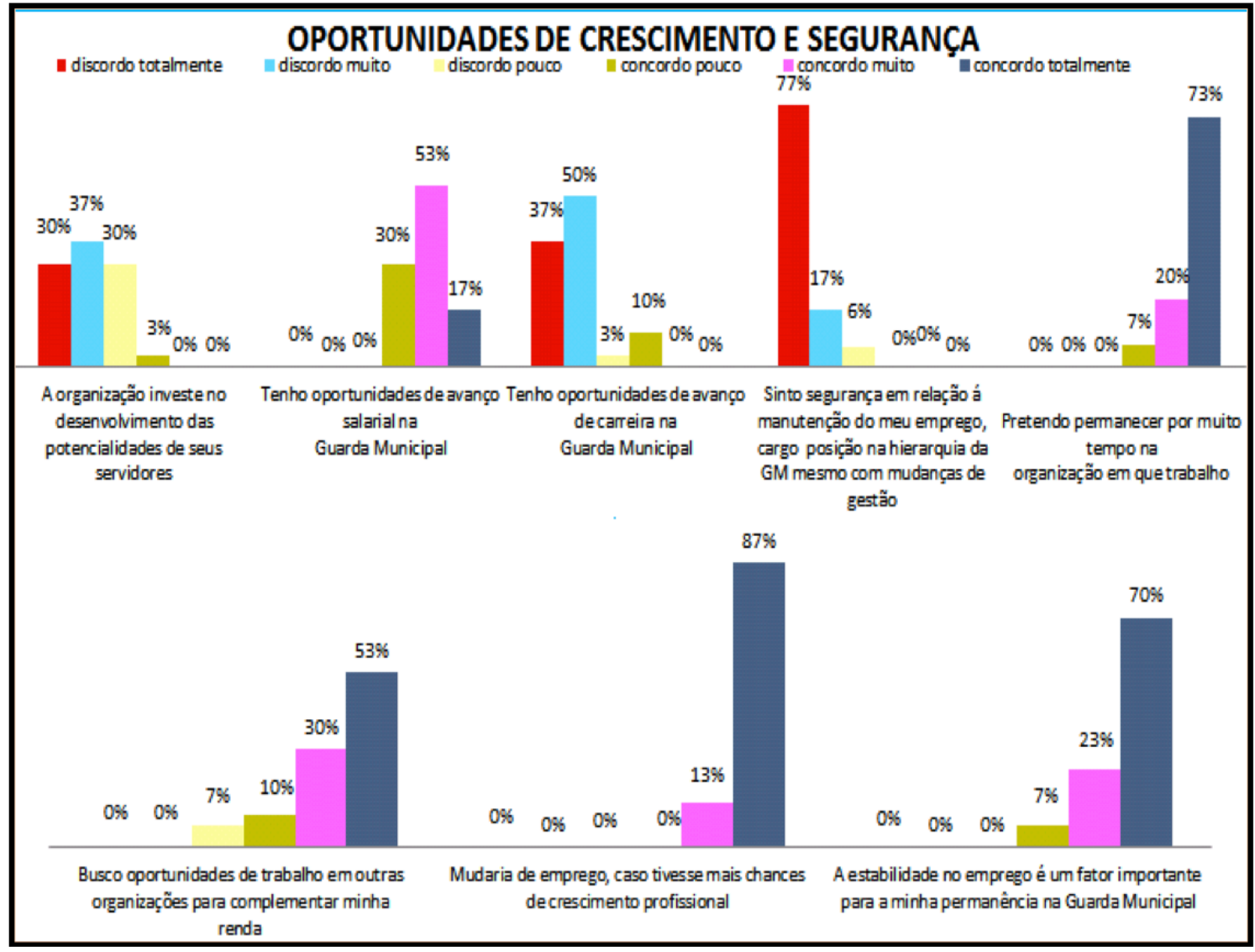

Fonte: Dados da pesquisa setembro/2017

O gráfico 04 apresenta sobre os fatores de oportunidade de crescimento e segurança no trabalho na visão dos Guardas municipais de Mossoró/RN, de acordo com esse critério, o modelo proposto por Walton (1973) mostra que sua análise demonstra como a organização contribui para o crescimento profissional do funcionário. Dessa forma, os indicadores realizados foram sobre se a organização investia no desenvolvimento das potencialidades de seus servidores, sendo que $97 \%$ dos respondentes discordaram totalmente, muito e pouco e apenas 3\% concordaram pouco. Em relação às oportunidades de avanço salarial na Guarda Municipal, 100\% dos respondentes concordaram totalmente, muito e pouco.

Outro indicador foi sobre as oportunidades de avanço de carreira na Guarda Municipal, pois $90 \%$ dos respondentes discordaram totalmente, muito e pouco. Percebe-se que em relação ao sentimento de segurança com á manutenção do emprego, cargo ou hierarquia mesmo com mudança de gestão, um total de $100 \%$ dos respondentes discordaram totalmente, muito e pouco. Outro indicador foi em relação a variável da pretensão em permanecer por muito tempo na organização, diante disso o total de $100 \%$ dos respondentes concordaram totalmente, muito e pouco.

O indicador sobre a buscar de oportunidade de trabalho em outros lugares para complementar a renda os quais $93 \%$ dos respondentes concordaram totalmente, muito e pouco e apenas $7 \%$ discordaram pouco. Em relação á mudança de emprego um total de $100 \%$ dos respondentes concordaram totalmente e muito, caso tivesse mais chances de crescimento profissional. Entretanto, em relação à estabilidade no emprego ser fator importante para permanecer na Guarda Municipal 100\% dos respondentes 
concordaram totalmente, muito e pouco.

Portanto, o aumento da expectativa de vida, maior tempo de vida trabalhando em atividades produtivas maior consciência do direito a saúde, apelos a novos hábitos e estilos comportamentais, responsabilidade social e consolidação do compromisso com a sustentabilidade. (LIMONGI-FRANCA, 2009).

\subsubsection{Síntese de fator de oportunidade de crescimento e segurança}

As tabelas referem-se aos fatores de oportunidade de crescimento sendo divididos os questionamentos em duas partes, oportunidades de crescimento e segurança " $\mathrm{A}$ " e oportunidades de crescimento e segurança "B".

Tabela 06 - Oportunidade de crescimento e segurança

SINTESE DE FATOR DE OPORTUNIDADE DE CRESCIMENTO E SEGURANÇA "A"

\begin{tabular}{|c|c|c|c|c|c|c|c|}
\hline & \multicolumn{3}{|c|}{ DISCORDO } & \multicolumn{3}{|c|}{ CONCORDO } & \multirow{2}{*}{$\begin{array}{l}\text { TOTAIS } \\
(\%)\end{array}$} \\
\hline & $\begin{array}{c}\text { Discordo } \\
\text { Totalmente } \\
(\%) \\
\end{array}$ & $\begin{array}{l}\text { Discordo } \\
\text { muito } \\
(\%)\end{array}$ & $\begin{array}{c}\text { Discordo } \\
\text { pouco } \\
(\%)\end{array}$ & $\begin{array}{c}\text { Concordo } \\
\text { pouco } \\
(\%)\end{array}$ & $\begin{array}{c}\text { Concordo } \\
\text { muito } \\
(\%)\end{array}$ & $\begin{array}{c}\text { Concordo } \\
\text { Totalmente } \\
(\%)\end{array}$ & \\
\hline Investimento / desenvolvimento & 30 & 37 & 30 & 3 & 0 & 0 & 100 \\
\hline Possibilidade de avanço salarial & 0 & 0 & 0 & 30 & 53 & 17 & 100 \\
\hline Possibilidade de avanço carreira & 37 & 50 & 3 & 10 & 0 & 0 & 100 \\
\hline Segurança no emprego & 77 & 17 & 6 & 0 & 0 & 0 & 100 \\
\hline Pretente permancer & 0 & 0 & 0 & 7 & 20 & 73 & 100 \\
\hline Conjunto (\%) & 29 & 21 & 8 & 10 & 15 & 18 & 100 \\
\hline
\end{tabular}

Fonte: Dados da pesquisa setembro/2017

A tabela "06" analisou a variável de acordo com os níveis de concordância e discordância demonstrando que um total de $57 \%$ dos guardas municipais discordam e $43 \%$ concordam, dessa forma, conclui-se que os respondentes pretendem permanecer no emprego por muito tempo mais não tem segurança no emprego, como também de avanço na carreira, já em relação a aumentos de salários, a organização possui um plano de cargos e salários, que possibilitam os guardas municipais a avanço salarial. 
SINTESE DE FATOR DE OPORTUNIDADE DE CRESCIMENTO E SEGURANÇA "B"

\begin{tabular}{|c|c|c|c|c|c|c|c|}
\hline & \multicolumn{3}{|c|}{ DISCORDO } & \multicolumn{3}{|c|}{ CONCORDO } & \multirow{2}{*}{$\begin{array}{c}\text { TOTAIS } \\
(\%)\end{array}$} \\
\hline & $\begin{array}{c}\text { Discordo } \\
\text { Totalmente } \\
(\%)\end{array}$ & $\begin{array}{c}\text { Discordo } \\
\text { muito } \\
(\%)\end{array}$ & $\begin{array}{l}\text { Discordo } \\
\text { pouco } \\
(\%)\end{array}$ & $\begin{array}{c}\text { Concordo } \\
\text { pouco } \\
(\%)\end{array}$ & $\begin{array}{l}\text { Concordo } \\
\text { muito } \\
(\%)\end{array}$ & $\begin{array}{c}\text { Concordo } \\
\text { Totalmente } \\
\text { (\%) }\end{array}$ & \\
\hline Estabilidade fator permanencia & 0 & 0 & 0 & 7 & 23 & 70 & 100 \\
\hline Busco Dportunidades & 0 & 0 & 7 & 10 & 30 & 53 & 100 \\
\hline Mudaria de emprego & 0 & 0 & 0 & 0 & 13 & 87 & 100 \\
\hline Conjunto (\%) & 0 & 0 & 2 & 6 & 22 & 70 & 100 \\
\hline Totais agrupados (\%) & & 2 & & & 98 & & \\
\hline
\end{tabular}

Fonte: Dados da pesquisa setembro/2017

A tabela "07" demonstrou um total de $98 \%$ dos respondentes "concordaram" e $2 \%$ dos respondentes "discordaram". Portanto concluem-se que a estabilidade é um fator permanente para continuar na organização, entretanto, os respondentes mudaria de emprego como também buscam outras oportunidades. Para Morin (2001), quando o servidor tem ciência da direção do trabalho e seus objetivos são claros e valorizados, abrem oportunidades de desenvolver suas capacidades e competências, pois conseguem participar da etapa de cada do processo resultando na sua valorização e satisfação no trabalho colhendo bons resultados.

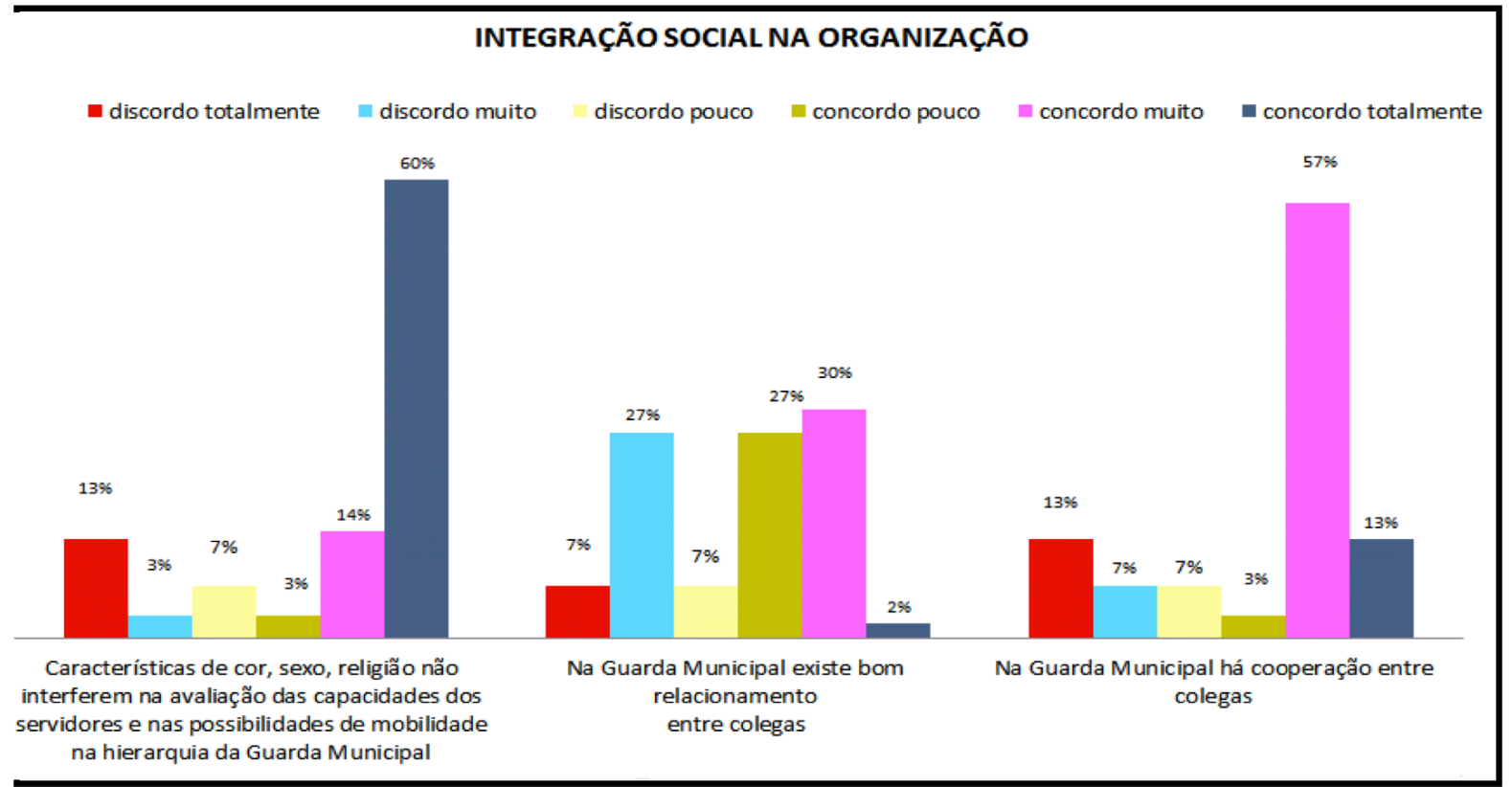

Figura 05 -Integração social na Organização

Fonte: Dados da pesquisa setembro/2017

Segundo o gráfico 05 que trata dos fatores de integração social na organização na visão dos Guardas municipais de Mossoró/RN, demonstram que analisar a integração social na organização contribui para atender aos fatores de qualidade de vida no trabalho. Dessa forma, os indicadores propostos são sobre as características de cor, sexo e religião se os mesmos interferem na avaliação das capacidades dos servidores e nas possibilidades de mobilidade na hierarquia da guarda municipal, 


\section{ISSN - 2447-178X}

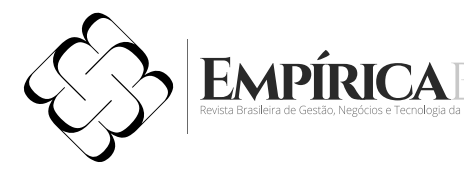

sendo que $77 \%$ dos respondentes concordaram totalmente, muito e pouco e apenas $23 \%$ discordaram totalmente, muito e pouco.

O segundo indicador foi em relação ao bom relacionamento entre colegas na guarda municipal, pois de acordo com os respondentes $59 \%$ concordaram totalmente, muito e pouco e apenas $41 \%$ discordaram totalmente, muito e pouco. Outro indicador foi em relação à cooperação entre colegas na guarda municipal, pois segundo $73 \%$ dos respondentes concordaram totalmente, muito e pouco e apenas $27 \%$ discordaram totalmente, muito e pouco.

\subsubsection{Síntese de fator de integração social na organização}

Tabela 08 - Integração social na organização

SINTESE DE FATOR INTEGRAÇÃO SOCIAL NA ORGANIZAÇÃO

\begin{tabular}{ccccccccc}
\hline & \multicolumn{3}{c|}{ DISCORDO } & \multicolumn{5}{c}{ CONCORDO } \\
\hline & $\begin{array}{c}\text { Discordo } \\
\text { Totalmente } \\
(\%)\end{array}$ & $\begin{array}{c}\text { Discordo } \\
\text { muito } \\
(\%)\end{array}$ & $\begin{array}{c}\text { Discordo } \\
\text { pouco } \\
(\%)\end{array}$ & $\begin{array}{c}\text { Concordo } \\
\text { pouco } \\
(\%)\end{array}$ & $\begin{array}{c}\text { Concordo } \\
\text { muito } \\
(\%)\end{array}$ & $\begin{array}{c}\text { Concordo } \\
\text { Totalmente } \\
(\%)\end{array}$ & $(\%)$ \\
\hline Não existe preconceito & 13 & 3 & 7 & 3 & 14 & 60 & 100 \\
Há bom relacionamento & 7 & 27 & 7 & 27 & 30 & 2 & 100 \\
Há cooperação & 13 & 7 & 7 & 3 & 57 & 13 & 100 \\
\hline Conjunto (\%) & 11 & 12 & 7 & 11 & 34 & 25 & 100 \\
\hline Totais agrupados (\%) & & 30 & & & 70 & &
\end{tabular}

Fonte: Dados da pesquisa setembro/2017

O fator de integração social na organização analisou-se a variável de acordo com os níveis de concordância e discordância demonstrando que um total de 70\% dos guardas municipais "concordaram" e 30\% "discordaram". Dessa forma, constata-se que na organização o índice de preconceito é baixo. Em relação aos fatores de cooperação no ambiente de trabalho e bom relacionamento o índice encontrando foi bom demonstrando que na organização há cooperação e um bom relacionamento entre os colegas. Portanto, para Walton (1973) a "humanização do trabalho e responsabilidade social da empresa envolvendo o atendimento das necessidades e aspirações do indivíduo". 
CONSTITUCIONALISMO

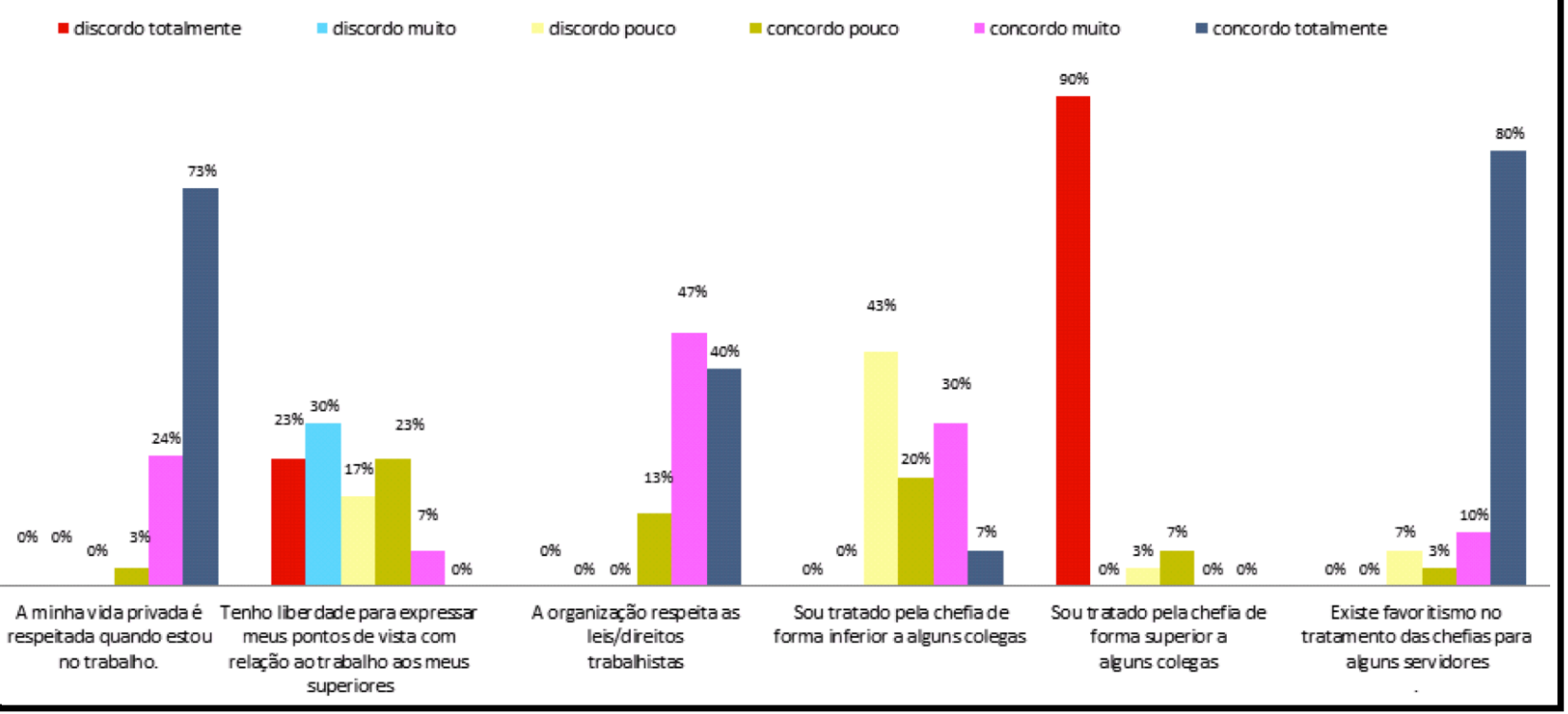

Figura 06 -Constitucionalismo

Fonte: Dados da pesquisa setembro/2017

De acordo com o gráfico 06 que demonstra a variável constitucionalismo da organização na percepção dos Guardas municipais de Mossoró/RN, pelo modelo proposto por Walton (1973) para tanto, os indicadores foram os seguintes aos GCM`S, se a vida privada era respeitada quando estava no trabalho, pois $100 \%$ responderam que concordaram totalmente, muito e pouco. Outro indicador foi sobre a liberdade para expressar os pontos de vista com relação ao trabalho e aos seus superiores, sendo que $70 \%$ dos respondentes discordam totalmente, muito e pouco e $30 \%$ concordaram muito e pouco.

Em relação á organização respeitar as leis e direitos trabalhistas, 100\% concordaram totalmente, muito e pouco. Já em relação ao indicador referente ao tratamento da chefia de forma inferior a alguns colegas, $57 \%$ concordaram totalmente, muito e pouco e $43 \%$ discordaram pouco. Já em relação ao tratamento pela chefia de forma superior a alguns colegas, $93 \%$ dos respondentes discordaram totalmente e pouco e apenas $7 \%$ concordaram pouco. Outro indicador foi sobre o favoritismo da chefia para alguns servidores, nesse quesito $93 \%$ concordaram totalmente, muito e pouco e apenas $7 \%$ discordaram pouco.

\subsubsection{Síntese de fator de constitucionalismo}

O fator de constitucionalismo foi dividido em duas partes sendo representado por constitucionalismo "A" e constitucionalismo "B" analisando a variável de acordo com os níveis de concordância e discordância. 
SINTESE DE FATOR CONSTITUCIONALISMO A

\begin{tabular}{|c|c|c|c|c|c|c|c|}
\hline & \multicolumn{3}{|c|}{ DISCORDO } & \multicolumn{3}{|c|}{ CONCORDO } & \multirow{2}{*}{$\begin{array}{c}\text { TOTAIS } \\
(\%)\end{array}$} \\
\hline & $\begin{array}{c}\text { Discordo } \\
\text { Totalmente } \\
(\%)\end{array}$ & $\begin{array}{c}\text { Discordo } \\
\text { muito } \\
(\%)\end{array}$ & $\begin{array}{c}\text { Discordo } \\
\text { pouco } \\
(\%)\end{array}$ & $\begin{array}{c}\text { Concordo } \\
\text { pouco } \\
(\%)\end{array}$ & $\begin{array}{c}\text { Concordo } \\
\text { muito } \\
(\%)\end{array}$ & $\begin{array}{c}\text { Concordo } \\
\text { Totalmente } \\
(\%)\end{array}$ & \\
\hline Há respeito ás leisddireito & 0 & 0 & 0 & 13 & 47 & 40 & 100 \\
\hline Há liberdade de expressão & 23 & 30 & 17 & 23 & 7 & 0 & 100 \\
\hline Há respeito á privacidade & 0 & 0 & 0 & 3 & 24 & 73 & 100 \\
\hline Conjunto $(\%)$ & 8 & 10 & 6 & 13 & 26 & 38 & 100 \\
\hline Totais agrupados (\%) & & 23 & & & 77 & & \\
\hline
\end{tabular}

Fonte: Dados da pesquisa setembro/2017

O fator " $\mathrm{A}$ " teve representado pela tabela 09 um total de $77 \%$ dos guardas municipais que "concordaram" e um total de $23 \%$ que "discordaram".

Tabela 10 - Constitucionalismo

SINTESE DE FATOR CONSTITUCIONALISMO B

\begin{tabular}{|c|c|c|c|c|c|c|c|}
\hline & \multicolumn{3}{|c|}{ DISCORDO } & \multicolumn{3}{|c|}{ CONCORDO } & \multirow{2}{*}{$\begin{array}{c}\text { TOTAIS } \\
(\%)\end{array}$} \\
\hline & $\begin{array}{c}\text { Discordo } \\
\text { Totalmente } \\
(\%)\end{array}$ & $\begin{array}{l}\text { Discordo } \\
\text { muito } \\
(\%)\end{array}$ & $\begin{array}{c}\text { Discordo } \\
\text { pouco } \\
(\%)\end{array}$ & $\begin{array}{c}\text { Concordo } \\
\text { pouco } \\
(\%)\end{array}$ & $\begin{array}{c}\text { Concordo } \\
\text { muito } \\
(\%)\end{array}$ & $\begin{array}{c}\text { Concordo } \\
\text { Totalmente } \\
\text { (\%) }\end{array}$ & \\
\hline Tratamento superior & 90 & 0 & 3 & 7 & 0 & 0 & 100 \\
\hline Tratamento inferior & 0 & 0 & 43 & 20 & 30 & 7 & 100 \\
\hline Existe favoritismo & 0 & 0 & 7 & 3 & 10 & 80 & 100 \\
\hline Conjunto $(\%)$ & 30 & 0 & 18 & 10 & 13 & 29 & 100 \\
\hline Totais agrupados (\%) & & 48 & & & 52 & & \\
\hline
\end{tabular}

A analise do fator B representado pela tabela 10 teve um total de $52 \%$ de guardas municipais que responderam que concordaram seguidos de $48 \%$ que discordaram.

Portanto, conclui-se que as variáveis representadas por este fator mostram os pontos que a organização necessita melhora, como as variáveis de favoritismo e liberdade de expressão, sendo importante para atender os aspectos de qualidade de vida no trabalho. Pois segundo Granjeiro (2002, p. 23), o conjunto de órgãos e entidades destinados a satisfazer, de forma regular e contínua, as necessidades sociais nos termos da lei. 
a discordo totalmente miscordo mu to discordo pouco m concordo pouco a concordo mu to $n$ concordo totalmente

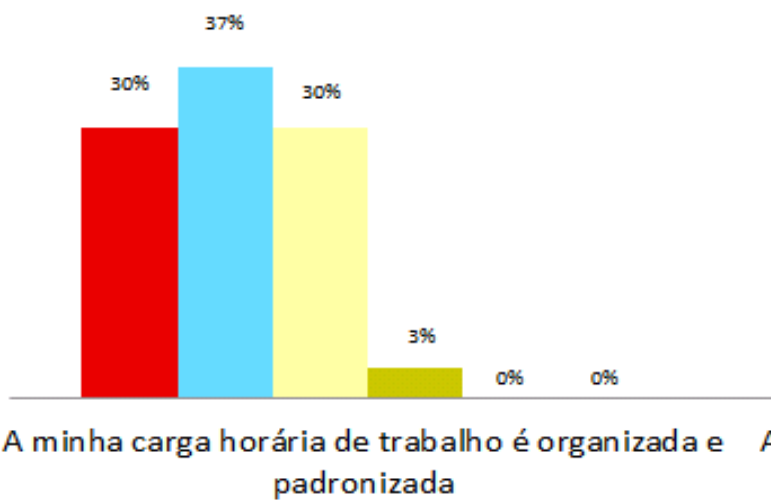
padronizada $53 \%$

scordo pouco $=$ concordo pouco m concordo mu to $\square$ concordo tota

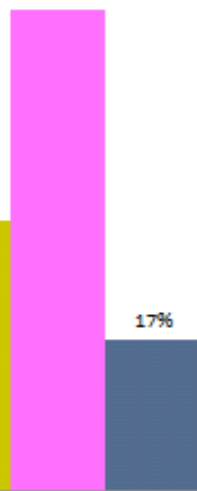
A minha carga horária me permite desfrutar tempo com a família e atividades de lazer

Figura 07 -Trabalho e o espaço total de vida

Fonte: Dados da pesquisa setembro/2017

Segundo o gráfico 07 apresenta a variável referente á trabalho e o espaço total de vida da organização na percepção dos Guardas municipais de Mossoró/RN, diante disso, o modelo de proposto por Walton (1973) afirma que o trabalho faz parte do espaço da vida do colaborador, dessa forma esse fator contribui para atender aos critérios de qualidade de vida no trabalho. Portanto, os seguintes indicadores mostram que os guardas municipais tem uma carga horária de trabalho é organizada e padronizada, pois $97 \%$ dos respondentes discordaram totalmente, muito e pouco e apenas $3 \%$ concordaram pouco, pois outro indicador foi em relação à carga horária permite desfrutar de tempo com a família e atividade de lazer, uma vez que $100 \%$ concordaram totalmente, muito e pouco.

\subsubsection{Síntese de fator de trabalho e espaço total de vida}

Tabela 11 - Trabalho e espaço total de vida

SINTESE DE FATOR DE TRABALHO E ESPAÇO TOTAL DE VIDA

\begin{tabular}{|c|c|c|c|c|c|c|c|}
\hline & \multicolumn{3}{|c|}{ DISCORDO } & \multicolumn{3}{|c|}{ CONCORDO } & \multirow{2}{*}{$\begin{array}{c}\text { TOTAIS } \\
(\%)\end{array}$} \\
\hline & $\begin{array}{c}\text { Discordo } \\
\text { Totalmente } \\
(\%)\end{array}$ & $\begin{array}{l}\text { Discordo } \\
\text { muito } \\
(\%)\end{array}$ & $\begin{array}{c}\text { Discordo } \\
\text { pouco } \\
(\%)\end{array}$ & $\begin{array}{c}\text { Concordo } \\
\text { pouco } \\
(\%)\end{array}$ & $\begin{array}{l}\text { Concordo } \\
\text { muito } \\
(\%)\end{array}$ & $\begin{array}{c}\text { Concordo } \\
\text { Totalmente } \\
(\%)\end{array}$ & \\
\hline Carga horaria padronizada & 30 & 37 & 30 & 3 & 0 & 0 & 100 \\
\hline Carga horaria permite laser & 0 & 0 & 0 & 30 & 53 & 17 & 100 \\
\hline Conjunto (\%) & 15 & 19 & 15 & 17 & 27 & 9 & 100 \\
\hline Totais agrupados (\%) & & 48 & & & 52 & & \\
\hline
\end{tabular}




\section{ISSN - 2447-178X}

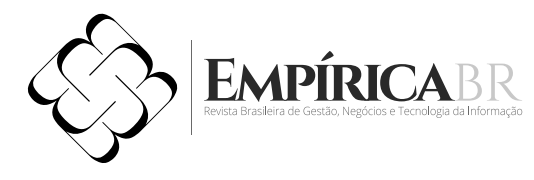

O fator de trabalho e espaço total de vida analisou-se a variável de acordo com os níveis de concordância e discordância demonstrando que um total de $52 \%$ dos guardas municipais "concordaram" e $48 \%$ "discordaram". De acordo com os questionamentos os guardas consideram que sua carga horária não é organizada e padronizada mais em compensação a mesma possibilita desfrutar de tempo com a família e com o laser. Portanto, o trabalho não deve absorver todo o tempo e energia do trabalhador em detrimento de sua vida familiar e particular, de seu lazer e atividades comunitárias. (WALTON, 1973)

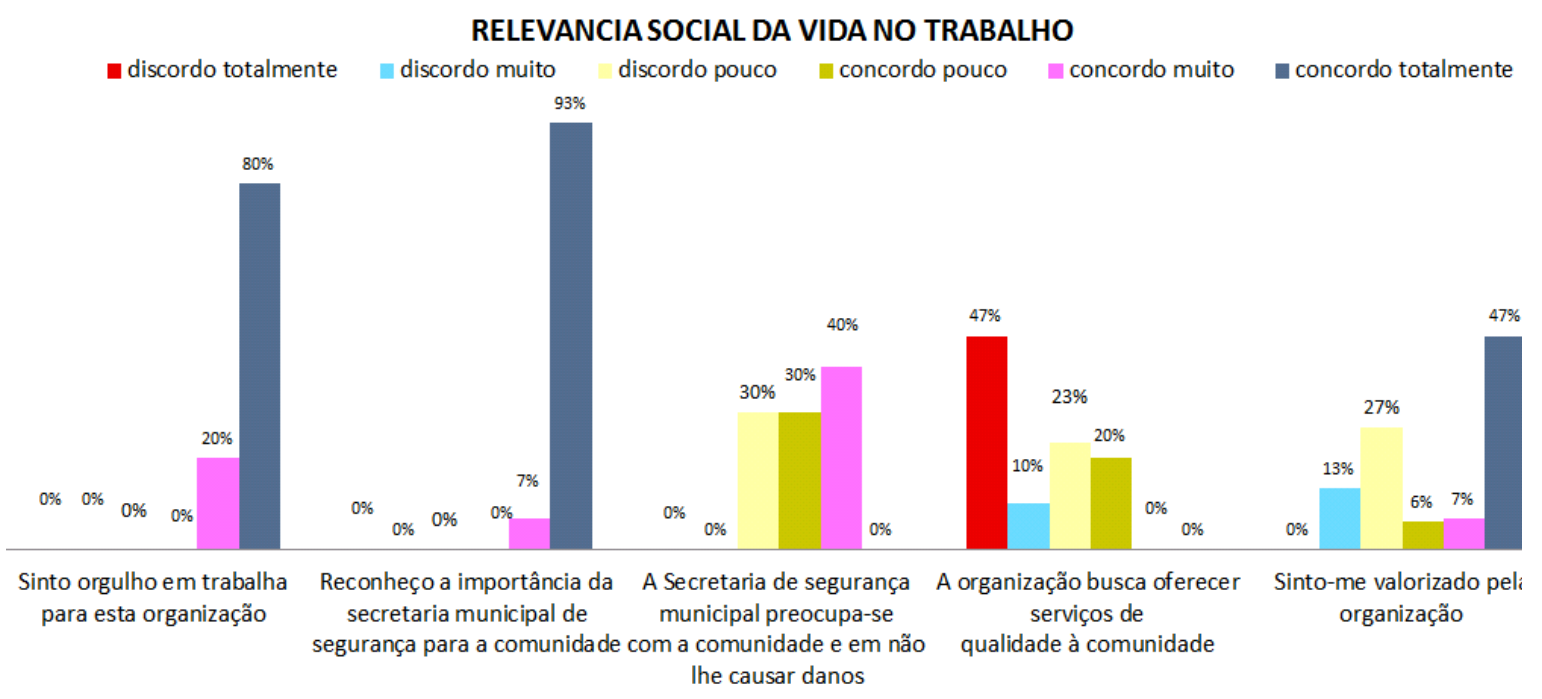

Figura 08 -Relevância social na vida no trabalho

Fonte: Dados da pesquisa setembro/2017

O gráfico 08 apresenta os fatores de relevância social na vida no trabalho na visão dos Guardas municipais de Mossoró/RN, nesse critério, o modelo proposto por Walton (1973) indica que sua análise é de suma importante para a organização. Dessa forma, os indicadores foram sobre o sentimento de orgulho em trabalhar na organização, sendo que um total de $100 \%$ dos respondentes concordaram totalmente e muito. Pois outro indicador foi em relação ao reconhecimento da importância da secretaria municipal de segurança para a comunidade, diante disso, 100\% concordaram totalmente e muito.

Os indicadores referentes à preocupação da secretaria de segurança municipal com a comunidade em não causar dados, $70 \%$ dos respondentes concordaram muito e pouco e $30 \%$ discordaram pouco, dessa forma para os respondentes a organização busca oferecer serviços de qualidade á comunidade, diante disso $80 \%$ dos responderam discordaram totalmente, muito e pouco e apenas $20 \%$ concordaram pouco. Em relação ao sentimento de ser valorizado pela organização, pois na visão dos respondentes $60 \%$ concordaram totalmente, muito e pouco e $40 \%$ discordaram muito e pouco. 


\subsubsection{Síntese de fator de relevância social do trabalho}

Tabela 12 - Relevância social do trabalho

\begin{tabular}{|c|c|c|c|c|c|c|c|}
\hline & \multicolumn{3}{|c|}{ DISCORDO } & \multicolumn{3}{|c|}{ CONCORDO } & \multirow{2}{*}{$\begin{array}{c}\text { TOTAIS } \\
(\%)\end{array}$} \\
\hline & $\begin{array}{l}\text { Discordo } \\
\text { Totalmente } \\
(\%)\end{array}$ & $\begin{array}{c}\text { Discordo } \\
\text { muito } \\
(\%)\end{array}$ & $\begin{array}{c}\text { Discordo } \\
\text { pouco } \\
(\%)\end{array}$ & $\begin{array}{c}\text { Concordo } \\
\text { pouco } \\
(\%)\end{array}$ & $\begin{array}{c}\text { Concordo } \\
\text { muito } \\
(\%)\end{array}$ & $\begin{array}{c}\text { Concordo } \\
\text { Totalmente } \\
\text { (\%) }\end{array}$ & \\
\hline Drgulho do trabalho & 0 & 0 & 0 & 0 & 20 & 80 & 100 \\
\hline $\begin{array}{l}\text { Importancia da secretária } \\
\text { municipal de segurança } \\
\text { Preocupação da segurança }\end{array}$ & 0 & 0 & 0 & 0 & 7 & 93 & 100 \\
\hline $\begin{array}{l}\text { municipal de segurança com a } \\
\text { comunidade }\end{array}$ & 0 & 0 & 30 & 30 & 40 & 0 & 100 \\
\hline serviços de qualidade & 47 & 10 & 23 & 20 & 0 & 0 & 100 \\
\hline valorização do servidor & 0 & 13 & 27 & 6 & 7 & 47 & 100 \\
\hline Conjunto (\%) & 9 & 5 & 16 & 11 & 15 & 44 & 100 \\
\hline
\end{tabular}

Fonte: Dados da pesquisa setembro/2017

O fator de relevância social analisou-se a variável de acordo com os níveis de concordância e discordância demonstrando que um total de $70 \%$ dos guardas municipais "concordaram" e $30 \%$ "discordaram". Portanto, conclui-se que as variáveis representadas pelos serviços que a organização oferece á comunidade apresentam pontos que podem melhorar para que tenha mais qualidade nos serviços. Na visão de Robbins (2009, p. 24), "o termo satisfação no trabalho refere-se a um conjunto de sentimentos que um indivíduo nutre em relação ao seu trabalho". Diante dos fatores de orgulho ao trabalho e a importância da secretária municipal de segurança para a comunidade, na visão dos guardas municipais á organização atende a esses critérios de forma satisfatória contribuindo então para a qualidade de vida no trabalho.

\section{CONSIDERAÇÕES FINAIS}

Neste artigo, procura-se mostrar a importância da qualidade de vida no trabalho sobre a visão dos guardas municipais de Mossoró/RN. Uma vez que é necessário possuir funcionários capacitados, preparados, motivados e satisfeitos, ou seja, que busquem sempre crescimento pessoal e profissional. Nesse contexto, a metodologia utilizada foi por meio de um questionário adaptado por Warken (2009) com questões numeradas de 1 á 6 de acordo com a escala Likert, sendo representada pelos fatores de discordância e concordância o qual foram aplicados 65 questionários obtendo uma amostragem no total de 30 respondentes no universo de 261 guardas municipais.

O embasamento teórico de Walton (1973) segue uma categoria de conceitos que visam subsidiar e construir uma estrutura de análise sobre qualidade de vida no trabalho. Uma vez que ao avaliar a QVT possibilita contribuir no processo de implantação de melhorias, pois quando se detecta os fatores é mais fácil propor melhorias, uma vez que a qualidade de vida no trabalho é um fator decisivo para um 
bom desempenho organizacional.

De acordo com a análise dos fatores que interferem a qualidade de vida no trabalho dos servidores públicos pesquisados, verifica-se que os oitos fatores proposto pelo método de Walton (1973), interferem no ambiente interno dos respondentes da pesquisa, entretanto, percebe-se que a insatisfação é um fator presente, principalmente nos aspectos como remuneração, condição de trabalho, condições de segurança, feedback, estresse, valorização, manutenção da estrutura física e saúde no trabalho, oportunidade de avanços na carreira.

Por outro lado, os resultados alcançados na pesquisa mostram também que alguns fatores contribuem para promover a motivação, bem-estar e a satisfação dos servidores esses critérios atende os fatores de qualidade de vida no trabalho, como orgulho no desempenho das funções, a importância do trabalho dos guardas municipais perante á comunidade, o respeito que a organização tem pelas leis e direitos dos trabalhadores, pois a carga horária permite desfrutar do tempo com a família e também com o laser, esses são fatores positivos da qualidade de vida no trabalho na organização em estudo. Dessa forma, a qualidade de vida no trabalho está ligado diretamente com a satisfação do servidor perante o ambiente de trabalho isso envolve os fatores físicos, saúde e segurança.

Conclui-se, portanto, que os guardas municipais de Mossoró/RN buscam harmonia dentro do ambiente de trabalho, pois existe a necessidade de criar um ambiente de participação e interação com os superiores e os colegas de trabalho. Dessa forma, valorizar o servidor no desenvolvimento das atividades e demonstrando a importância do seu trabalho para a organização e a comunidade. Como sugestão a futuras pesquisas a temática viabiliza diversos estudos atribuindo pesquisas a diversos segmentos de mercado tanto na esfera pública como na esfera privada uma vez que a qualidade de vida no trabalho estará presente em todos ambiente de trabalho, necessitando de avaliações constantes.

\section{REFERÊNCIAS}

1. Bergamini, C. W. A Difícil Administração das Motivações. Revista de Administração de Empresas 6-17, 1998.

2. BOM SUCESSO, Edina de Paula. Relações Interpessoais e Qualidade de Vida no Trabalho. São Paulo: Qualitymark, 2002.

3. CHIAVENATO, Idalberto. Iniciação à administração de recursos humanos. 4. ed. ver. e atualBarueri, São Paulo: Manole, 2010.

4. DOLAN, Simon, L; tradução de Jussara Simões; supervisão técnica Edson Ferreira. Estresse, Auto estima, saúde e trabalho. Rio de Janeiro: Qualitymark, 2006.

5. FERNANDES, Eda C. Qualidade de Vida no Trabalho: como medir para melhorar. Salvador, BA: Casa da Qualidade, 1996.

6. FERREIRA, V. C. P.; FORTUNA, A. A. M.; TACHIZAWA, T. Gestão com Pessoas: uma abordagem 


\section{ISSN - 2447-178X}

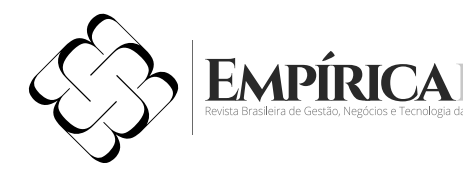

aplicada às estratégias de negócios. 5. ed. Rio de Janeiro: FGV, 2012.

7. GIL, Antônio Carlos. Gestão de Pessoas. Enfoque nos Papéis Profissionais. São Paulo, Atlas, 2007.

8. GIL, Antônio Carlos. Como Elaborar Projetos de Pesquisa. 6ª Ed. São Paulo: Atlas, 2010.

9. GRANJEIRO, J. Wilson. Administração Pública. 10. ed. Brasília: Vestcon, 2002.

10. LIMONGI-FRANÇA, Ana Cristina. QVT: conceitos e práticas nas empresas da sociedade pósindustrial. 2 ed. São Paulo: Atlas, 2009.

11. MAXIMIANO, Antônio Cesar Amauri. Introdução à administração. 5. ed. rev. e ampl. São Paulo: Atlas, 2005.

12. MORIN, E. M. Os Sentidos do Trabalho. RAE-Revista de Administração de Empresas, v. 41, n. 3, jul-set, p.8-19, 2001.

13. NEWSTROM, John W. e DAVIS, Keith. Comportamento Humano no Trabalho: uma abordagem organizacional. São Paulo: Pioneira Thomson, 2001.

14. PREFEITURA MUNICIPAL DE MOSSORÓ. Lei disponível em <http://www.guardacivilmossoro. com.br/2012/06/decreto-n-3482-regulamenta-estrutura.html>. Acesso em: 12 setembro. 2017.

15. PREFEITURA MUNICIPAL DE MOSSORÓ. Lei disponível em http://www.prefeiturademossoro. com.br/jom/jom23.pdf. Acesso em: 12 setembro. 2017.

16. PONTES, Benedito Rodrigues. Gestão de profissionais em empresas competitivas: como atrair e reter talentos. São Paulo: LTR, 2001.

17. RAUPP, F. M.; BEUREN, I. M. Metodologia de pesquisa aplicável às ciências sociais In: Como elaborar trabalhos monográficos em contabilidade: Teoria e Prática. 3ª ed. São Paulo: Atlas, 2006.

18. ROBBINS, S. P. Fundamentos do Comportamento Organizacional. São Paulo: Pearson Prentice Hall, 2009 .

19. RODRIGUES, Marcus Vinicius Carvalho. Qualidade de Vida no Trabalho: Evolução e Análise no Nível Gerencial. 4 ed. Vozes, Petrópolis, RJ, 1998.

20. Tadeucci, M. d. Motivação e Liderança. Curitiba: IESDE Brasil S.A. 2009.

21. WARKEN, Karoline. Qualidade de vida no trabalho: um estudo de caso na Guarda municipal de Porto Alegre. RS, 2009. Monografia (Graduação em Administração) - Universidade Federal do Rio Grande do Sul. Disponível em: < http://www.lume.ufrgs.br/handle/10183/19147pdf>. Acesso em: 02 setembro. 2017.

22. WALTON, Richard E. Quality of Working Life: What is it? Sloan Management Review, 15, 1, pp. $11-21,1973$. 